\title{
Community Perception of COVID-19: A Qualitative Approach through Applying the Health Belief Model
}

Gamachu Gishe ( $\nabla$ gamachugishe@gmail.com )

Madda Walabu University https://orcid.org/0000-0002-3699-1091

\section{Tamirat Hailu}

Madda Walabu University

\section{Rameto Aman}

Madda Walabu University

\section{Sisay Dango}

Madda Walabu University

\section{Research Article}

Keywords: COVID-19, Community, Susceptibility, Severity, perceived benefits, perceived barriers

Posted Date: December 21st, 2020

DOI: https://doi.org/10.21203/rs.3.rs-113275/v4

License: (c) (i) This work is licensed under a Creative Commons Attribution 4.0 International License. Read Full License 


\section{Abstract}

Background: The outbreak and rapid spread of the virus has not only affected the lives of hundreds of millions of families, but also has disrupted the pace of economic and social development.

Methods: The current study aimed to explore community perception about COVID -19 pandemic. An in depth exploratory design was utilized. Semi structured interviews were conducted with 45 participants aged between 26 and 70 years old. Besides, observation checklist was utilized.

Results: In the very beginning when few Corona Virus cases were reported, in general, people were scared to death. But as the number of infected cases reported more and more people have also became immune to the fear of corona virus. Even some section of people associated with a particular political ideology; assume that there is no corona virus at all. Hotels, cafeterias and shopping centres are not as cautious as they were in the beginning. As a result, streets are crowded and the public started living regular life. Therefore, the covid protocol like wearing face masks, using sanitizers, physical distance and all have become just a ritual.

Conclusions: It is evident that most of the government workers like bank employees, traffic police and all are well aware of Covid-19 preventive methods and consequences and try their best to make the people to be part of the fight against the pandemic. But the common people from different walks of life, some with ignorance, some with innocence and some with a particular political ideology defy and violate the WHO covid-19 protocol.

\section{Introduction}

The occurrence of COVID-19 pandemic has had multifaceted effect across the world. The outbreak and rapid spread of the virus has not only affected the lives of hundreds of millions of families, but also has disrupted the pace of economic and social development[1].

Moreover, the burden of health problems in Africa is proportionately higher than the rest of the world [2]. Consequently, the higher prevalence of malnutrition, anaemia, malaria, HIV/AID, and tuberculosis in many African countries may coincide with and worsen the on-going COVID-19 pandemic prevention and control measures in Africa [2]. To combat the enemy, [3] suggested social distancing including people taking crowded trains and attending weddings and social gatherings. As good experience a research conducted in South African suggested that religious and cultural activities of any form must be restricted at this time [4].

Likewise, recommended coffee shops and bars could have to change the way they served their customers before, relying on take away and perhaps charging them extra for use of indoor space [3]. Reputed scholars in the area of health psychology suggested that individual health decisions are determined by attitudes, lifestyles, and government policies [5]. 
More importantly, the Health Belief Model (HBM) asserts that change in behaviour is determined after consideration of severity, benefit, and barriers to change [6]. Similarly, [7] research in China noted that individuals' psychological status determine the likelihood of implementing preventive measures as those with stronger anxiety and fear tended to adopt more severe practices of mask wearing and hand hygiene.

According to the model one will engage in a health-related behaviour if one perceives susceptibility to an illness/condition that has severe consequences and that the benefits to the health related activities outweigh the barriers [8]. Health, belief model has seven elements. These are susceptibility to illness, severity of the illness, the costs involved in carrying out the benefits involved in carrying out the behaviour, Health motivation element reflects, barriers and cues to action/reminder of the severity [8].

[9] has applied HBM to treat cervical cancer. The HBM predicts regular screening if an individual perceives that she is highly susceptible to it. Similarly, [10] tested the effectiveness of health belief model in predicting mosquito control performances. Thus, dengue fever awareness campaigns that target peoples' beliefs may be most effective in eliciting mosquito prevention jobs. To treat major depression [8] have adopted health belief model and concluded that the main barrier preventing help-seeking was fear of the unknown treatment process and low self-efficacy.

[11] adopted HBM to teach adults about disease and their study suggest that perceptions of susceptibility and seriousness of health outcomes are related to individual's characteristics that is gender and age. In the same way, these results support the notion that when young adults feel susceptible to negative health outcomes and when health-care coverage is available, young adults will seek out preventive care services.

Current study areas, Robe and Shashemene towns, are the place where significant number of population makes in and out movement on daily basis. Therefore, the researchers were intended to address the following specific research objectives:

To explore community perceived susceptibility level of COVID-19 virus.

To identify community perceived severity level of COVID-19 disease.

To describe community perceived benefits of prevention measures of COVID-19 virus.

To identify community perceived barriers while implementing preventive measures of COVID-19 virus.

To point out self-efficacy level of community in the process of implementing the preventive measures of COVID-19 virus.

\section{Methods And Materials}

\section{Study Design}

To explore community perception of COVID -19 , we employed exploratory research design. The research was conducted from May to July 2020. 


\section{Participants}

Our participants are comprised of bank workers such as bank managers, front makers, guards, traffic polices, drivers, hotel and grocery managers. Purposive sampling technique was employed to select participants from all group of population. Moreover, for this research 45 individuals interviewed. Regarding to characteristics of participants, education, age, male and female aged between 26 and 70 years old, and the educational background from secondary school completed to second degree holders respectively.

\section{Tools of Data Collection}

Tools utilized in this study included interviews and observation with participants. Field notes were also collected during each interview. Semi-structured interview guide developed after reviewing related literature.

A sample item for perceived susceptibility is how seriously the participants erroneously believe that they are at risk for inevitably developing COVID-19. For perceived severity level, the participants were asked whether they believe in COVID-19 infection and its consequences are significant enough. Regarding preventive tools, key informants were asked how they think of the suggested prevention methods are worth enough to prevent fears, concerns and the COVID-19 by itself. To identify their self-efficacy about COVID-19, we asked the key informants how they believe in implementing the recommended preventive methods. Lastly, we asked the participants to explain the barriers they have been experiencing since the outbreak of the pandemic. In conclusion, observation checklist was used to observe people practices to contain the COVID-19 pandemic.

\section{Ethical consideration}

The procedures used in this study were approved by the research committee. Besides, the researchers strictly implemented [12] research code of conduct that researchers have to inform participants about the purpose of the research, expected duration, procedures, their right to participate or to withdraw during the research period. To sum up, before recording their voices, permission obtained from each key informant.

We completely implemented WHO directives such as physical distancing, wearing face mask and washing hands by sanitizers with $80 \%$ and above. Therefore, during data collection, the distance between researchers and each participant was at least at 2 meters. We also used selfie-stick to audio record the participants' opinion.

\section{Data Quality Assurance}

As the qualitative research demands, the researchers spent enough time with participants on site and explained the process of data collection to the participant's in detail. The entire research process was audio-recorded; field notes were taken and kept in protected place. The audio recorded data was transcribed by language experts. Ultimately, sufficient contextual information about the fieldwork sites is 
provided to transfer the instances of the phenomenon described in the research. So that the participants, researchers and other professionally concerned people can easily empathize with research sites and context.

\section{Methods of Data Analysis}

Thematic analysis was employed to analyse the data. Thus, during data transcription, researchers provided a label and collected it accordingly. Data categorization was done by reading the transcript several times. Finally, the results were presented according to the objective.

\section{Results And Discussion}

\section{Perceived Susceptibility Level}

The current findings seemed to indicate that most of the interviewees were highly susceptible to the pandemic. For example, all bank guards stated that due to close and frequent contact with customers they are extremely susceptible to be infected with corona virus-19.

Additionally, one traffic police viewed in this way:

"We are at considerable risk because when drivers break a law, we try to cease them and allegedly remove the cars plate. As a result, the drivers came with terribly constant distance implore us and sometimes touché us with their hands."

Another traffic police described collective vulnerability to the novel corona virus, because his anxious children came back home from Addis Ababa, the capital city of Ethiopia where the rate of confirmed case of COVID-19 is escalating rapidly than before. It would seem that it is not known how healthy they arrived; however, they prefer to live with their father and mother under whatever circumstance.

By using health belief model [6] noted that if one recognizes severity, benefit, and barriers of the disease, the odds of desirable behavioural change follow. In the same way, most of our Bank interviewees have indicated their customers carry money for transaction instead of using any banking technology. As a result, they felt terribly that they are vulnerable to COVID-19.

For example, one participant illustrated the following:

"If the cash is too much, we inform our customers to accommodate inside the insufficient room with no expectations of distance between our clients to count the cash. Our customers also put off their face masks while talking with bankers and communicating with someone else with the phone because they assume they might not be attended to."

The finding indicated that the premium customers had a tendency to act out, because they desire the banks to handle them as close as before. All drivers were terrifying because they travel from one area to another. 
Consequently, as a matter of coincidence, we approached one driver who willingly stopped driving due to fear of getting COVID-19. By standing in front of Shashemene town main bus station, he expressed his peculiar susceptibility to the pandemic as; "it has been one month since I stopped working because the disease scared me so much that the people do not care about and I fear to use facebook."

The current work is also supported by [9] that if an individual perceives that she/she is extremely susceptible to cancer of the cervix, that the benefits of routine screening are high, and that the costs of such action are comparatively low.

\section{Perceived Severity Level}

The key informants agreed that no disease was notorious as COVID-19 because the pandemic severely hurts all nations regardless of their personal background. Furthermore, other participants remarkably noted that at first; everyone was shocked when the disease outbreak in Ethiopia but now it looks like people adapt it. Similarly, a hotel manager at Robe town shared his views as far as the severity of the disease is concerned:

"COVID-19 is incredibly dangerous, that I find myself stay clean without terribly worrying about it. As a precaution, we ensure that we all hotel staff use face masks, sanitize ourselves frequently because, we have repeated contact with money and we often tell our waitress or waiters to keep their distance when ordered by a customer and we allow a maximum of three persons to sit on one table."

Conversely, the findings disclosed that there were many people who have information about disease and assumed as if there was no corona virus in Ethiopia. In this manner, careless people are reluctantly taking COVID-19 pandemic as simple as common cold and the flu because they perceive as the disease does not kill because they constantly caught by it.

\section{Perceived Benefits of preventive tools and Self-efficacy Level}

Alongside interviewing the target participants, the researchers were observing some hotels at both towns to see how people are treating the pandemic. In most of the hotels, customers are not allowed to take a seat and share one table by more than three individuals and every worker put face mask on and has personal sanitizer.

We also asked how they serve customers who rent their bed. One hotel manager replied; "as you can see, we offer an accommodation service to our clients by keeping our bedrooms tidy and purify it regularly."

More importantly, this interviewee reported that us they have been providing brief description about pandemic early in the morning once in a week to hotel workers before they commence their work. In addition to this, their hotel has posted instructions in written form visibly on the walls inside for the one who rent the bed about disease pathways and other precautions to be done. In addition, the waiters were cleaning the seats and dining tables by sanitizer soon after their primary customers left. 
The experiences of Awash Bank also seem engaging in a manner of speaking not allowed to wear hand gloves, because they assume that if bankers wearied a glove, it would have protected only the one who wears it, but it could not support their customers from this virus. Likewise, one female employer of Awash Bank argued that "we might forget to sanitize our hands frequently and we contact our clients' pass book and cash with our gloved hand so, we can easily transfer the virus to our clients."

On the other side, a bank manager suggested people to maximize the use of modern technology for the services such as transfer of money through their mobile and ATM among numerous services given by the bank. The participant was directly relating it to the most reliable method that is stay at home therefore, they can definitely get the services they need and to reduce their contact with the bank because being at home would keep away them from getting infected.

To identify the perceived self - efficacy level of participants, one driver reported the following; "I take precautions to prevent the disease. I clean my hands frequently with a sanitizer and wear a face mask and we do not allow those who do not use face masks to enter our cars."

In the same way, traffic police goes further as stated by health professionals to prevent the disease, using a glove while touching metal objects, washing hands often and refrain from touching the nose and eyes.

In addition to this, one more traffic police insisted an intelligent use of preventive measures to fight against the spread of COVID-19. The detail is quoted hereunder:

"Once we confronted a convicted driver; we put on hand gloves, face masks and maintain physical distance while removing the car plate number, checking on extra passengers, reading exit paper shown by the drivers."

All traffic police asserted that they have been working hard to reduce the spread of the disease by warning the people to use face masks and punishing drivers who violate declared state of emergency to save the people from the virus. As it was reported by [7] individuals' psychological status determines implementation of preventive measures.

\section{Perceived Barriers and Cues to Action}

As it was reported, community preventive strategies usage patterns are not completely accurate. A hotel manager noted that some people with face masks don't cover their mouth and nose. Some use dirty and over used face masks. Some even believe that one who wears a face mask is actually infected that's why he/she is wearing face mask.

Moreover, one banker was apt to disclose that their customers become even more vulnerable because they have been buying and using a face masks sold on the street which is possibly affected by a lot of people to get the bank services inside. Consequently, a bank guard reported serious challenges he came across at the gate of his bank one of the client came without mask and he informed him to wear his mask unless he can't get in and then the customer shared his friend's mask. 
In the same way, a bank manager insisted that there were clients who put masks in their pockets or on their bag after they got in. A traffic police viewed that as far as the disease is concerned people can be divided into two. The first group are those who possess enough knowledge about the disease, but they don't practice it, the second groups are those who don't possess enough knowledge about COVID-19 and unable to use the advice of health experts due to economy and lack of accessibility to hear from different medias. He assumed that relative to the second group, people who recognize the disease well are not practicing preventive measures.

In most of the hotels and groceries, the researchers observed hand washing materials alongside water, soap and sanitizer were placed in front of the gate though majority of their customers reluctant to use it. One of the hotel managers reported the following:

"Customers do not wash hands. When insisted to wash, customers say that they have already washed. The same is true with face masks. Customers say that they are free of virus therefore, no need to wear masks unless one is really infected."

People are not only misusing the face mask but also physical distancing and sanitizer. Evidences obtained from diverse interviewees noted that in some places there is still a hand shaking especially when relatives come across each other. Furthermore, another participant reported that at the market the two parties are still shaking each other hand where no one wears a face mask.

Many participants agreed that since Ethiopians inclusive and integrated life style is also aggravating the spread of the disease because neighbours called one another to drink coffee and caring children of one another. According to the participants, avoiding the social gatherings like coffee ceremonies is considered as serious cultural and social violation. In another instance, a bank worker shared his own experience at his home: "Some of my relatives from rural area visited me and when I requested them to wash their hands; they assumed that I am rude to them. One really hates people in this kind of difficult times."

A driver would cling to his confidence in preventive measures, despite their clients' irrational belief; "it is getting ridiculous people believed as there is no disease since most of them insult me when I ask them to use a face mask. My sole uses do not deter me from the disease since all are teasing."

A research conducted in South Africa by [4] suggested that religious and cultural activities of any form have to be restricted. Simultaneously there is also evidence that suggests an awareness gap among the community in implementing the preventive measures. It was exposed that there are until now people who claim as there is no virus in Ethiopia and other people relate the virus with politics because they have a belief that the government doesn't want to conduct elections. Besides, there was thinking that the government is not reporting numbers of infected cases on the media as other countries do.

\section{Conclusion}


It is evident that most of the government workers like bank employees, traffic police and all are well aware of Covid-19 preventive methods and consequences and try their best to make the people to be part of the fight against the pandemic. But the common people from different walks of life, some with ignorance, some with innocence and some with a particular political ideology defy and violate the WHO covid-19 protocol. Since different commodities are distributed from Addis Ababa, where the prevalence of the disease is ridiculously high, to various Ethiopian regions, people should take maximum care the way they handle the goods.

Similarly, hotels, restaurants, groceries, banks, drivers, shop keepers, police and all the others have a great responsibility in fighting against the pandemic in their own capacity. As far as Covid-19 is concerned, any amount of awareness programs cannot be more. Therefore, on behalf of the government, the awareness programs must continue and should take them to the people as much as possible.

\section{Declarations}

\section{Consent for publication}

Not applicable.

\section{Funding}

The authors received financial support for the research from Madda Walabu University Research Community Engagement and Technology Transfer Vice President Office. The funder has no role in designing, analysis, edition and publication of the finding.

\section{Authors' contributions}

Gamachu Gishe and Tamirat Hailu conceived, designed, involved in the data collection, transcribed data, analysed the data and prepared the manuscript. Ramato Aman conceived, designed the study and took part on data collection. Sisay Dagno was involved in proposal writing. All authors have read and approved the finished manuscript.

\section{Acknowledgements}

We would like to thank Madda Walabu University Research Community Engagement and Technology Transfer Vice President Office for providing the chance to compete with other university staff during proposal defence. Once again thank you for providing a fund to us alongside managerial support from the beginning to the end.

\section{Competing interests}

The authors declared no potential conflicts of interest with respect to the research, authorship and/or publication of this article. 


\section{References}

[1] Gao X, Yu J. Public governance mechanism in the prevention and control of the COVID-19: information, decision-making and execution, Journal of Chinese Governance. 2020; https://DOI:10.1080/23812346.2020.1744922.

[2] Rutayisirea E, Nkundimana G, Mitonga KH, Boyed A, Nikwigizea S. What works and what does not work in response to COVID-19 prevention and control in Africa. International Journal of Infectious Diseases. 2020; https://doi.org/10.1016/j.ijid.2020.06.024.

[3] Sharfudding S. The world after Covid-19. The Commonwealth Journal of International Affairs. 2020; Volume 109,issue 3.

[4] Jaja FI, Anyanwu UM, Jaja IC-I. Social distancing: how religion, culture and burial ceremony undermine the effort to curb COVID-19 in South Africa, Emerging Microbes \& Infections. 2020; 9:1, 1077-1079, https://DOI:10.1080/22221751.2020.1769501.

[5] D'souza C, Zyngier S, Robinson P, Schlotterlein M, Sullivan-Mort G. Health Belief Model: Evaluating Marketing Promotion in a Public Vaccination Program. Journal of Nonprofit \& Public Sector Marketing. 2011; 23.134-157, https://DOI:10.1080/10495142.2011.572668.

[6] Tariku B, Whiting JS, Mulualem D, Singh P. Application of the Health Belief Model to Teach Complementary Feeding Messages in Ethiopia, Ecology of Food and Nutrition.2015; 54:5, 572-582, https://DOI:10.1080/03670244.2015.1049344.

[7] Yang H, Bin P, He JA. Opinions from the Epicenter: an online survey of university students in Wuhan amidst the COVID-19 outbreak1, Journal of Chinese Governance. 2020; https://DOI:10.1080/23812346.2020.1745411.

[8] Castonguay J, Filer RC, Pitts JM. Seeking Help for Depression: Applying the Health Belief Model to Illness Narratives, Southern Communication Journal.2016;

https://DOI:10.1080/1041794X.2016.1165729.

[9] Ogden J. Health Psychology. A Text Book. 3rd ed. Open University Press, New York, USA. 2004.

[10] Thompson F, Caltabiano LM. The Health Belief Model and dengue fever preventative behaviors: A pilot programme, International Journal of Health Promotion and Education. 2010;48:1, 9-19, https://DOI:10.1080/14635240.2010.10708175.

[11] Luquis RR, Kensinger SW. Applying the Health Belief Model to assess prevention services among young adults, International Journal of Health Promotion and Education. 2018; https://DOI:10.1080/14635240.2018.1549958.6. 
[12] APA. Ethical Principles of Psychologists and Code of Conduct. American Psychological Association 2017. 